\title{
86589 - MORTALIDADE POR INFLUENZA EM IDOSOS NO RS EM 2018: UM ESTUDO TRANSVERSAL
}

\author{
Apresentação Oral - Geriatria
}

Pedro Pablo de Gusmão Bonilla / Bonilla, PPG / GHC; Andrea Morais de Gusmão / Gusmão, AM / Prefeitura Municipal de Porto Alegre

Introdução: as infecções respiratórias constituem um conjunto de doenças comumente relacionadas aos idosos, sendo o vírus da Influenza um dos seus principais agentes etiológicos. Os idosos são um grupo vulnerável porque a idade avançada está associada com uma grande prevalência de doenças crônicas e um sistema imune mais deficiente. No Brasil, a política de vacinação contra a Influenza iniciou-se em 1999, sendo oferecida anualmente pelo SUS aos idosos e demais grupos de risco. Objetivos: analisar o número de casos e óbitos por Influenza no estado do Rio Grande do Sul e comparar o coeficiente de mortalidade entre os idosos e o restante da população. Métodos: estudo transversal com análise secundária dos dados presentes nos boletins epidemiológicos divulgados pelo Centro Estadual de Vigilância em Saúde (CEVS) até a 41a semana (13/10) de 2018. Resultados: durante o período analisado, no Rio Grande do Sul, houve 613 casos de Síndrome Respiratória Aguda Grave (SRAG) por Influenza, dos quais, 25,9\% (159 casos) foram em adultos maiores que 60 anos. Além disso, dos 94 óbitos, 41 foram em idosos, representando 43,6\% do total. O coeficiente de mortalidade nos idosos foi 2,2 vezes maior do que no restante da população. Conclusões: durante o período analisado, os idosos foram o grupo com a maior mortalidade por complicações respiratórias causadas pela Influenza. Reforça-se, então, a importância da vacinação nos idosos, que durante o ano de 2018 atingiu uma cobertura de 93,9\%, considerada acima da meta proposta pelo Ministério da Saúde.

Palavras-chave: mortalidade; influenza; idosos.

Referências: 1. Freitas EV, Py L et al. Tratado de Geriatria e Gerontologia - 3a․ed - Rio de Janeiro: Guanabara Koogan, 2013. Pág:165-170; 2. Ministério da Saúde, Secretaria de Vigilância em Saúde. Doenças Infecciosas e Parasitárias - Guia de Bolso. 8ª ed. Brasília: MS, 2010. Pág:17-37; 3. Site do Ministério da Saúde: http://www.saude.gov.br/saude-de-a-z/gripe; 4. Site do Centro Estadual de Vigilância em Saúde do RS: https:/www.cevs.rs.gov.br/upload/arquivos/201810/16130427-boletim-semanal-flu-se-41.pdf. 